\title{
Australia's influenza pandemic preparedness plans: an analysis
}

\author{
Ralf Itzwerth $^{1} \cdot$ Aye Moa $^{1} \cdot$ C. Raina MacIntyre ${ }^{1,2}$
}

Published online: 24 November 2017

(C) Macmillan Publishers Ltd., part of Springer Nature 2017

\begin{abstract}
We analysed Australian plans issued by the public sector and current at the time of the last human pandemic in 2009. They came from various levels of governance, and offered guidance in key domains. Using 13 established criteria, we rated 10 plans (national, state, and territorial) for their usefulness to guide health and medical intervention, business continuity, and crisis communication, plus consideration of at-risk populations. The intended end-user of most plans was not clear, whether hospital manager, health worker, or policy maker. Scores ranged from 8 to 29 of a maximum possible of 39, with many inconsistencies between plans. Health system-related issues were better addressed than critical infrastructure and essential systems resilience. The needs of Indigenous populations and use of pneumococcal vaccination and antibiotics were rarely considered in plans. Pandemic response would be more effective if plans were standardised, clear, and were to include overlooked dimensions of a pandemic's impact as well as guidance for specified end-users.
\end{abstract}

Keywords Pandemic $\cdot$ Preparedness plans · Influenza $\cdot$ Emergency $\cdot$ Public health

Aye Moa

a.moa@unsw.edu.au

1 School of Public Health and Community Medicine, The University of New South Wales,

UNSW Sydney, Sydney, NSW, Australia

2 College of Public Service and Community Solutions, Arizona State University, Tempe, AZ 85287, USA 


\section{Background}

An influenza pandemic is a rare, high impact event. Few have occurred. Governments must plan, because the health, economic, and social impact of a pandemic can be sudden and severe. Challenges include dealing with inherent uncertainty and anticipating the "worst-case scenario" [1]. Pandemic plans assume that many conditions and circumstances will remain under control, and that needed resources will be available.

Each government should update its legal authority to promote alignment with the directive of the World Health Organization's (WHO) Global Agenda on Influenza for the development and implementation of national preparedness plans [2, 3]. Most pandemic plans use a worst-case scenario with features drawn from 1918 [4-7]. Methods for anticipating possible consequences based on these estimates extend beyond traditional strategic planning [8-10].

The scope of pandemic plans is influenced by culture, beliefs, and perspectives of the planner and of the intended users [11]. Soon after its 56th World Health Assembly in 2003, a WHO directive called for member states to prepare for influenza pandemics [12]. Hong Kong published the first (unofficial) plan in 1997 following the avian influenza outbreak there. Since then, governments worldwide have drawn up pandemic plans based on the assumption of a pandemic arising from highly pathogenic H5N1 ("bird flu"). Aside from dealing with increased morbidity and mortality and strengthening the 'surge capacity' of a health system, the next most crucial task is the prevention or mitigation of any interruption of "essential services". These include continuation of power supplies, water, transport, and telecommunication upon which business continuity depends.

In its Comparative analysis of national pandemic influenza preparedness plans, the WHO listed the following elements of the assessment of the state or quality of preparedness plans: (1) planning and coordination, (2) situation monitoring and assessment, (3) prevention and containment, (4) health system response, and (5) communication [13]. A subsequent analysis of European plans found many plans fail to address preparation for disruption of essential services [14].

World Health Organization called for plans to guide users in three key domains: health and medical intervention, continuity of organisation, and crisis communication. Under health, plans should address measures relevant to public health including vaccination, hygiene, quarantine, and drugs such as antivirals. Under organisation, plans should address responsibilities of authorities plus legal and administrative frameworks. This includes essential supplies, services, and staff. Crisis communication should be part of the overall governance and management of any disaster [15]. Plans often assume that hospitals will remain operational and will be able to attend to the quickly rising number of patients; in addition, plans address hospital surge capacity during pandemic.

We aimed to review official Australian pandemic preparedness planning documents in place at the time of the 2009 pandemic; to identify areas of consistencies, inconsistencies, and gaps; to determine clarity and ease of 
interpretation for end-users; and to compare thoroughness of planning for health and medical functions versus critical infrastructure.

\section{Methods}

We identified and collected documents from 2008 to 2009 that indicated in their titles relevance for pandemic influenza preparedness during the pandemic of 2009 . We conducted a review of Australian and State Government sources in print, on official websites, and from other internet resources. We reviewed plans by supranational organisations such as the WHO.

We constructed a typology based on types of pandemic planning documents [16]. We identified subsets of organisational units as 'authors' including departmental units with jurisdiction over pandemic-related activities, such as 'Health', 'Transport', 'Attorney-General's Department'. We found 160 documents. Documents at State, Territory, and National levels were retained for the study. We categorised the plans using internationally accepted planning standards informed by the International Organization for Standardization (ISO) [17, 18], the literature on project management [19], and pandemic planning controls [20-22].

Following criteria and a checklist established by WHO [21, 23], we sought to assess plans representing state, Commonwealth, and supranational bodies on details for planning health and essential services. We reviewed each document for its coverage of (1) health and medical intervention, (2) continuity of the organisation, and (3) crisis communication.

We also assessed consideration of specific needs of Aboriginal and Torres Strait Islanders, and populations at-risk for complications of influenza [24]. We searched Australian plans because of reports that the needs of these populations had been overlooked in pandemic planning [25].

We used the methodological approach of Mounier-Jack et al. in their analysis of European plans [26]. We considered a document to be relevant to pandemic preparedness if it specified pandemic planning as its purpose, and if it had been issued by the Australian Federal or State Governments, and was current just before or during in the year 2009.

Overall, we selected 10 Australian preparedness plans. Our sample contained two Australian Government plans and one from each of the eight Australian states or territories (see listing of plans in Tables 2 and 3). We examined each for its usefulness for informing readers about health- and non-health-related measures in Australia.

\section{Scoring of plans}

Pandemic preparedness plans are meant to cover a wide range of topics including readiness of hospitals and availability of health supplies, especially of relevant drugs and pharmaceuticals usually stockpiled in anticipation. We classified these as 'health criteria'. We classified as 'non-health criteria' the technical and organisational aspects (for example, equipment and communication, respectively) and a 
range of underlying or interconnected enabling systems ("essential goods and services").

We assigned six categories to rate plans against the WHO Influenza Pandemic Preparedness Checklist [23]. We ranked plans under two categories: (a) guidance related to hygiene, health, and treatment ("health factors planning") and (b) guidance related to essential/critical systems ("critical systems' planning"). We applied a scale to assess a plan's standard interventions for pandemic planning: "personal hygiene", "social distancing", "vaccines", antivirals", "antibiotics", "pneumococcal vaccines", and instructions regarding the use of drugs. Pneumococcal vaccine and antibiotics prevent and treat secondary bacterial infections that may result from pandemic influenza. We also checked for statements regarding the special needs of Aboriginal and Torres Strait Islander people in each plan [27].

We scored plans next on their references to external systems, and critical and essential services. Table 1 shows major dimensions of the infrastructure components and systems summarised.

Two members of our team independently scored the categories (RI, CRM). Where the reviewers' assessments differed by two points or more, they discussed until they were able to reach agreement. Scores for each criterion ranged from a possible $0-3$, with 3 representing complete and comprehensive instructions, 2 making general remarks about the topic, 1 offering at least the keyword in the text, and 0 representing no mention of it. The maximum possible score for health criteria for any plan was 21 , and for non-health criteria was 18 . While there is some subjectivity in scoring 1-3, the score of zero was not contestable, as it reflects the absence of consideration of a variable.

\section{Results}

The search for planning documents yielded 160 items from which we identified 10 as eligible. In reviewing those, we found health interventions to have been covered more comprehensively than essential services, although most noted the importance of essential services. Each approached pandemic planning as a serious undertaking. Several offered strategies to reduce or prevent death and disease.

Table 2 shows the health-related criteria. Most of the plans assumed preparation would be for a worst-case scenario based on the 1918 experience. We found extensive variations in the level of detail on personal hygiene, social distancing (to avoid transmission), and the use of medications and drugs. While some documents (Plans 1, 3, and 5) emphasised hygiene or vaccination (Plan 4), others (Plans 2, 6, 7, and 8) only mentioned it or some pointed to other sources (Table 2). The most comprehensive plan, Plan 5 (Victoria) [28], presented readers with consistent details on "external systems" and all "health-related intervention" options including antibiotics and pneumococcal vaccines. The latter two topics were not mentioned by almost half of the reviewed plans.

Table 3 shows critical infrastructure considerations. All but two plans (Plans 5, 8) failed to provide details of critical/essential systems, apparently assuming such systems would remain intact (Table 3). Plans did not provide adequate 
Table 1 Essential infrastructure

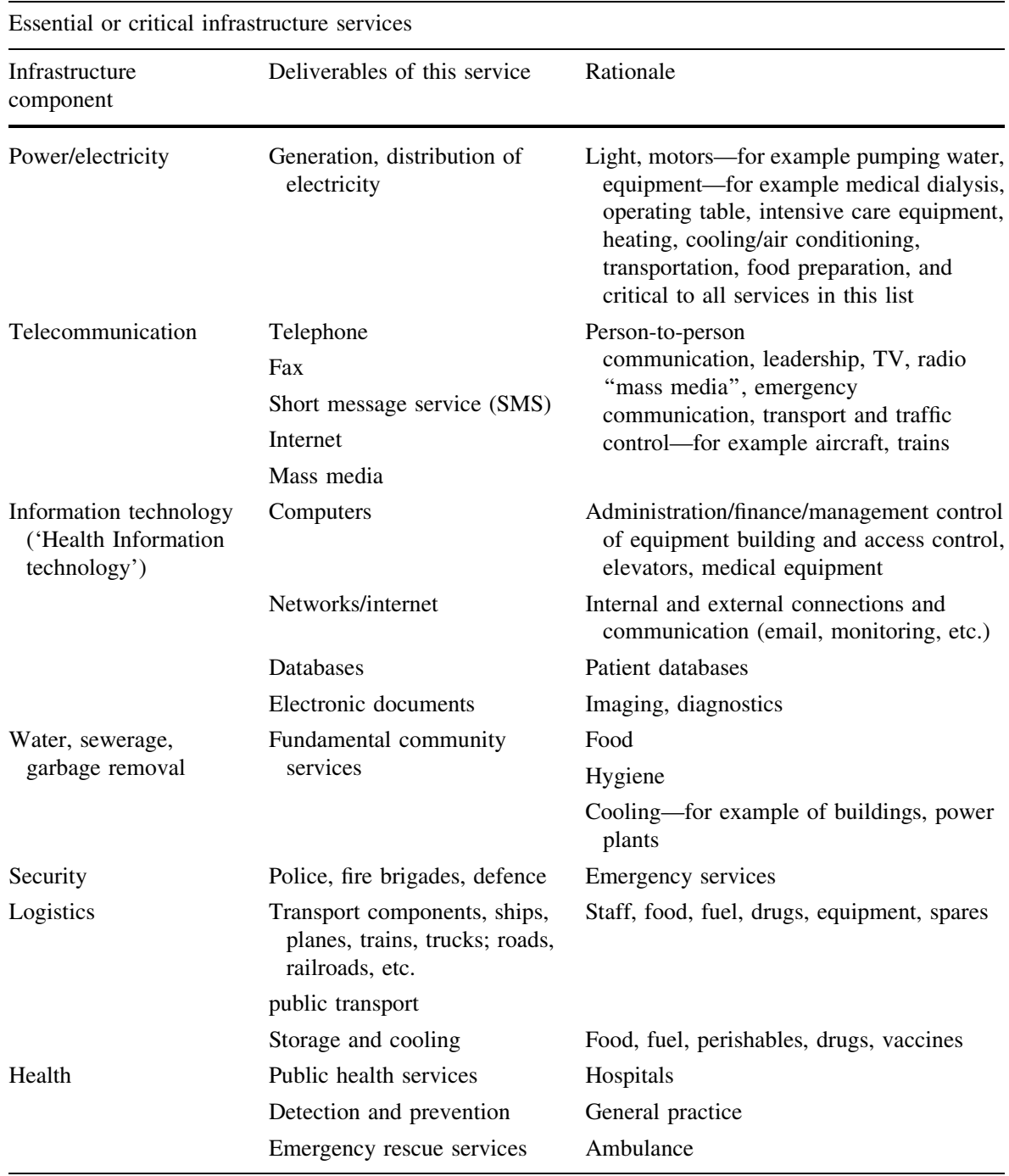

consideration of potential failure of critical elements during an emergency. One (Plan 5) that introduced 'infrastructure' noted it "assists individuals and communities in the management of their daily lives, but also forms an important role of community identity". Four out of the 10 plans made no reference to the need for power and utilities or for any preparation to ensure their availability. Two plans (6 and 7) did not mention "essential systems".

Seven of the 10 plans failed to mention computerised systems necessary for communication and databases. Four plans (2, 3, 4, and 7) included very little about the importance of electricity supplies and telecommunications. Most proposed preparedness measures that relied on the availability of uninterrupted critical 
R. Itzwerth et al.

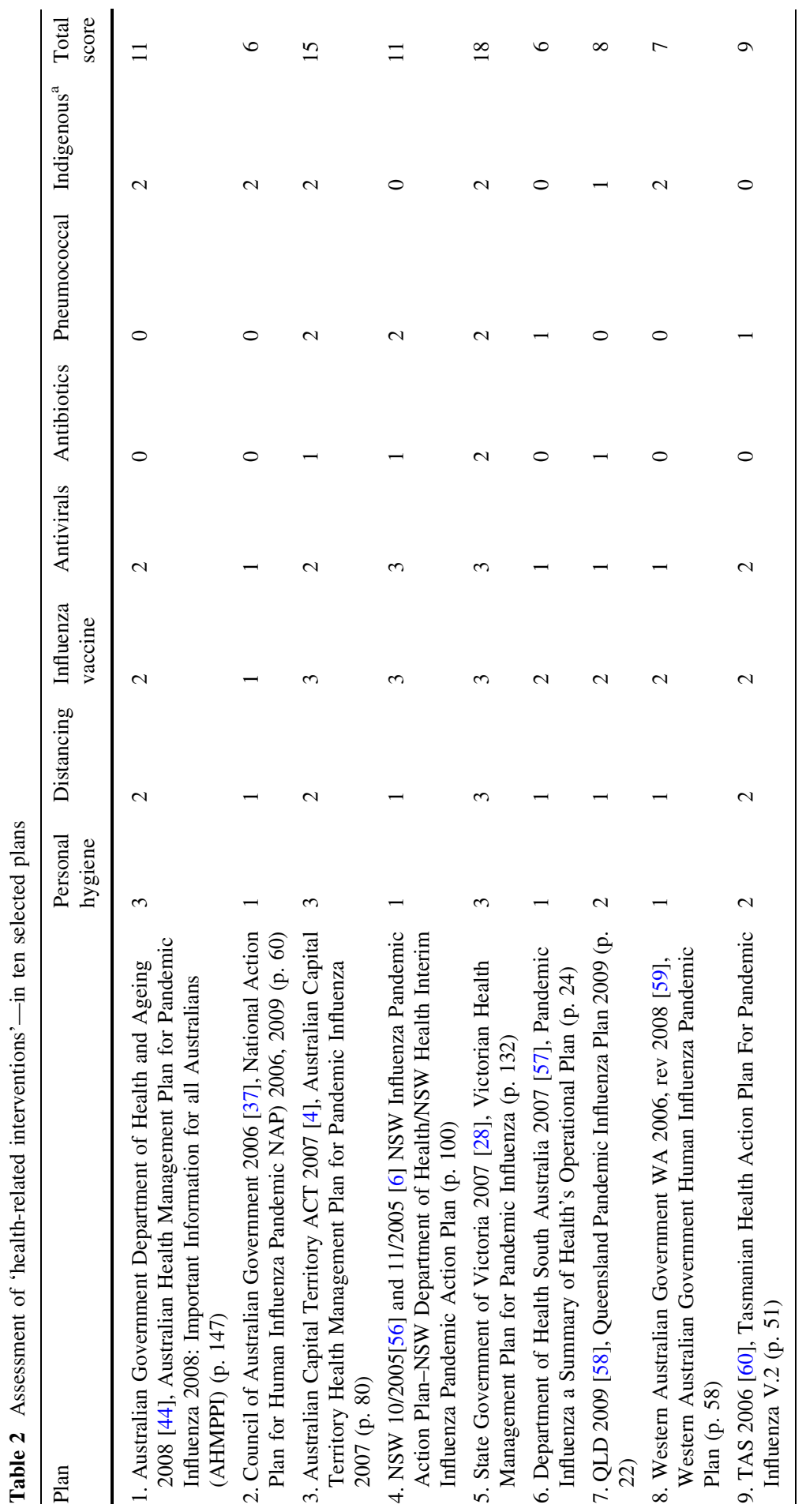




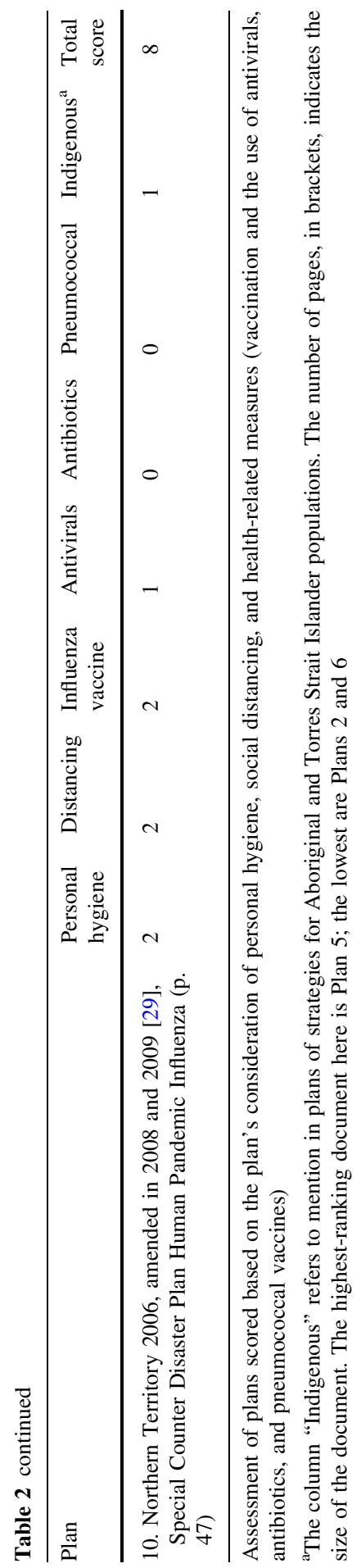




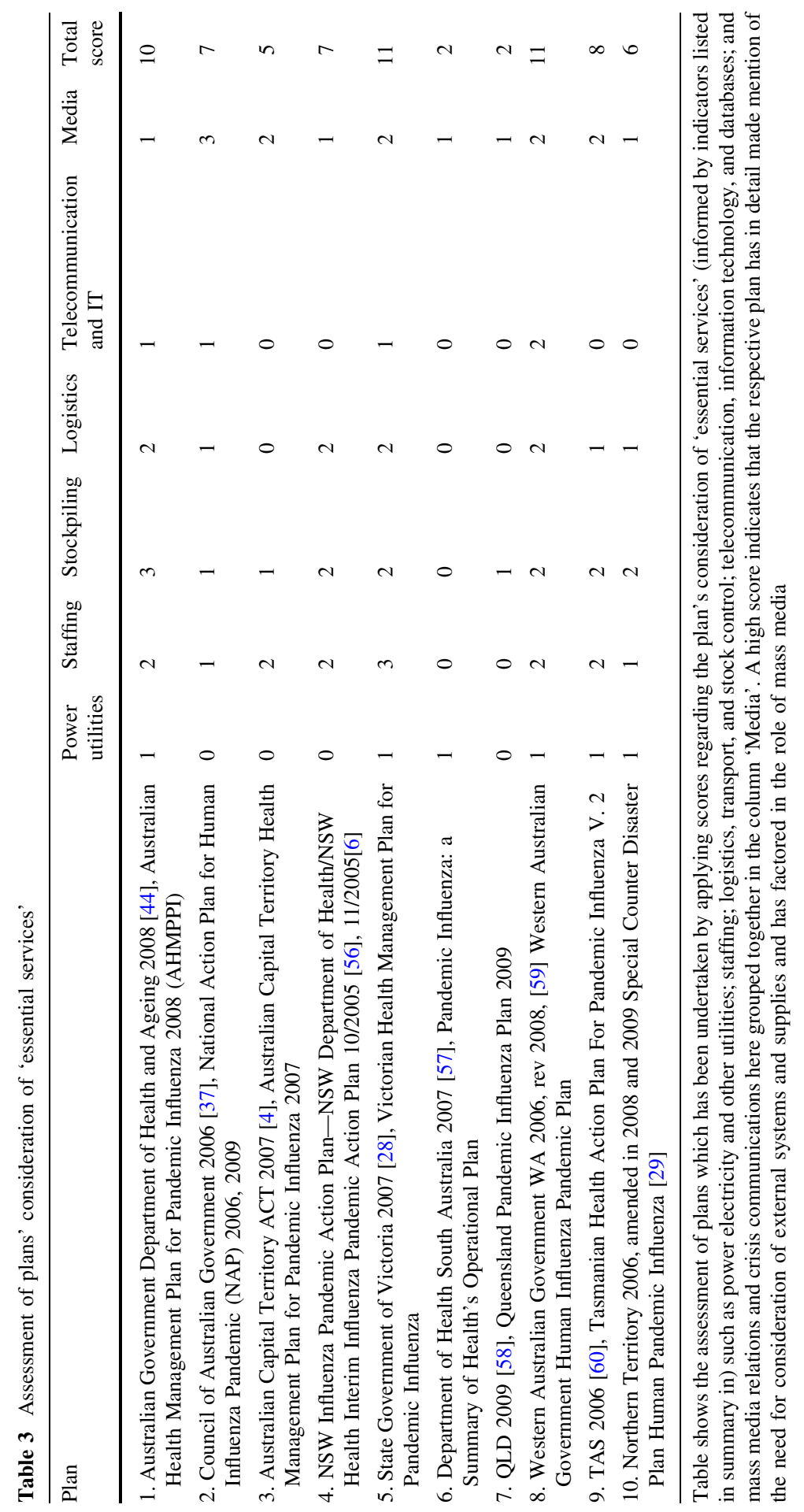


services such as internet or computers. The pandemic outbreak of 2009 helps us to understand the importance of reliable and continuous information and media interaction and crisis communication (Table 3). This feature appeared prominently in non-pandemic-related disaster plans. Only one (Plan 2) discussed the need for crisis communication in detail and provided instructions. No plans mentioned the use of social media.

Staffing and absenteeism. Two plans did not mention staff absenteeism during pandemics (6 and 9). Staffing in hospitals and stockpiling of drugs, often discussed in conjunction with transport, are closely related to health; three plans $(1,5$, and 8) discussed them in detail.

Plans other than Plan 2 appeared to be 'top-down', describing "State governance arrangements" or " how government will work" rather than what steps organisations should take. One plan provided "additional information" in appendices or as attachments (Plan 10) [29].

Overall, information about "health-related interventions", especially influenza vaccination, was better than that about "external systems". Four plans ranked in the bottom half in both categories. Five of ten plans did not mention pneumococcal vaccines, and 6 of 10 did not mention antibiotics.

The same plans that scored high on "health-related intervention" also contained the most information on "essential services" (Plans 3 and 5). Plan 5 (Victoria) ranked highest for both health (18/21 points) and non-health (11/18 points). Scores across plans ranged from 6 to 18 for health, and 2-11 for non-health criteria. Scores were low for Aboriginal and Torres Strait Islander needs in pandemic planning (Table 2). Indigenous people were not mentioned at all in 3 plans nor covered adequately in 2 other plans, and no plan received a score of 3 for this criterion.

\section{Discussion}

The influenza pandemic plans during the 2009 pandemic showed considerable variation in detail, consistency, completeness, and usability. Planning for critical infrastructure ranked consistently lower than the health coverage, making this as an area for improvement. A lack of clarity about the intended end-user (hospital manager, clinician, or health department policy maker) further limits the usefulness of these plans.

The WHO had recommended planners to pay "attention to the need to ensure adequate supplies of vaccine, antiviral agents, and other vital medicines" [12, 30]. Yet coverage of pharmaceutical interventions varied widely, with some (antibiotics and pneumococcal vaccines) entirely omitted in several plans. Secondary bacterial infections are a major cause of preventable death and illness during pandemics, causing up to $30 \%$ of deaths [31]; therefore, prevention and treatment of bacterial complications should be routinely covered in pandemic plans.

Staffing and stockpiling of drugs dominate the interpretation of what might be considered under "essential services" with little attention to the need for power and telecommunications. Planners focused on the health system and assumed that the 
critical infrastructure upon which the health system depends would function normally. This is a vulnerability for continuity of any health system.

The literature addresses crisis communication as central to disaster management $[15,32,33]$ but only one plan addressed this well. Planners have not factored in the arrival and availability of internet-based social media and their potential usefulness or impact [34, 35].

The pandemic of 2009 caused disproportionate morbidity and mortality in Indigenous people [36]. The "Australian National Action Plan for Human Influenza Pandemic" [37] had simply overlooked Aboriginal and Torres Strait Islanders, a finding consistent with reports by other sources that these populations had been "forgotten" in core Australian planning documents [27]. Yet Aboriginal and Torres Strait Islander people are at higher risk for influenza and its complications and with an overall higher exposure to communicable diseases [38].

As early as 2006, the National Aboriginal Community Controlled Health Organisation had called for specific preparedness for Aboriginal and Torres Strait Islander populations, fearing they would be disproportionally affected in a pandemic [39]. The geographical remoteness of many communities and their often low socioeconomic status would make any outbreak potentially devastating [40]. Flint et al. showed a "disproportionate impact" with significant higher hospitalisation rates [41], and members of the Aboriginal population representing 20\% of confirmed cases of influenza [42]. Massey et al. stated that "It was clear to many respondents that the policies and plans had been developed without respectful engagement with communities and this was a barrier to their acceptance and implementation" [25].

Health care providers found generic planning documents to be useful and applied them in the field [43]. Revised versions of Australian planning documents [44] addressed the specific needs of vulnerable minorities [42, 45]. In the Australian Health Management Plan for Pandemic Influenza current in 2017, at-risk groups including the Aboriginal and Torres Strait Islander people are included, with recommendations for tailored health care services and other services [46].

Absenteeism of staff working in health care facilities dominates preparedness and preferential vaccination is often the top item mentioned [47]. Essential services outside of the health system may also be impacted by high rates of absenteeism, a possibility unaccounted for by many plans [48]. Any systemic failures could cripple systems that rely on power and telecommunication, and this in turn could disable the health system $[49,50]$. Governments do not own, nor have direct control over, most services and businesses that run components of "critical infrastructure" [51]. Even if able to intervene, in a crisis government may not have the expertise or resources to keep privatised systems operational should their owners become unavailable [52].

A limitation of most plans is lack of rigorous version control and vulnerability to political electoral cycles. Within less than 1 year from 2009 to 2010, almost half of all Australian State and Federal government website locations had changed, sometimes after an election, when the entire departments vanished or changed names. The Internet itself is a critical resource and highly dependent on others, something users and planners need to consider.

Preparedness plans need to incorporate established standards for good governance and business continuity. They need to apply evidence-based instruments and 
specify the intended audience or end-user $[53,54]$. Most plans do not include 'return to normal' guidance. That could be particularly useful for health services [55].

Limitations of this study include subjectivity in scoring of plans, despite our method for bringing the scorers to agreement through discussion. There are other vulnerable groups during a pandemic besides Indigenous people, such as pregnant women, health workers, the immunosuppressed; we did not examine attention to such groups, but this is a research gap that should be addressed.

\section{Conclusion}

Coordination, rationalisation, and the connection of pandemic planning across sectors and jurisdictions would result in better preparedness. Plans should apply standards; be consistent, easy to access, read, and comprehend; and address infrastructure domains of preparedness. Planners should include and consult with all categories of stakeholders, especially those most vulnerable. Prevention and treatment of bacterial pneumonia must be routinely included in pandemic plans.

The plans we reviewed at the onset of the 2009 pandemic have since been revised several times, including in late 2009, to address gaps which became apparent during the pandemic [51]. Planning for rare events of potentially high impact requires resources and tight cooperation. Despite availability of relevant knowledge, many plans appear to work from unsubstantiated assumptions and fail to consider proven methods. A single plan or a series of consistent plans, which are accessible, cover health and non-health factors, and specify intended end-users would improve pandemic preparedness.

\section{References}

1. Taubenberger JK, Morens DM. 1918 Influenza: the mother of all pandemics. Emerg Infect Dis. 2006;12(1):15-22.

2. Collins N, Litt J, Moore M, Winzenberg T, Shaw K. General practice: professional preparation for a pandemic. Med J Australia. 2006;185(10 Suppl):S66-9.

3. Stoehr K. The global agenda on influenza surveillance and control. Vaccine. 2003;21(16):1744-8.

4. Australian Capital Territory. Australian Capital Territory Health Management Plan for Pandemic Influenza 2007. In: Department of Health, editor. Canberra Australia, 2007. p. 80.

5. United Nations. Pandemic Planning and Preparedness Guidelines for the UN System. 2006. p. 53.

6. New South Wales Government NSW Health Interim Influenza Pandemic Action Plan. In: Department of Health, editor. Sydney, 2005. p. 100.

7. Communicable Diseases Network Australia New Zealand. A framework for an Australian Influenza pandemic plan. In: Canberra CDoHaAC, editor. Canberra: Dept. of Health and Aged Care; 1999. p. 179.

8. Varum CA, Melo C. Directions in scenario planning literature-A review of the past decades. Futures. 2010;42(4):355-69.

9. Neiner JA, Howze EH, Greaney ML. Using scenario planning in public health: anticipating alternative futures. Health Promot Pract. 2004;5(1):69-79.

10. Chermack TJ, Lynham SA, Ruona WEA. A review of scenario planning literature. Futures Res Q. 2001;7(2):7-32. 
11. Cerulo KA. Never saw it coming: cultural challenges to envisioning the worst. Chicago: University of Chicago Press; 2006.

12. World Health Organization. Prevention and control of influenza pandemics and annual epidemicsfifty-sixth World Health Assembly.: WHO; 2003.

13. World Health Organization. Comparative analysis of national pandemic influenza preparedness plans. WHO; 2011.

14. Mounier-Jack S, Coker RJ. How prepared is Europe for pandemic influenza? An analysis of National Plans. Lancet. 2006;367:1405-11.

15. World Health Organization. Outbreak communication-best practices for communicating with the public during an outbreak. In: Report of the WHO Expert Consultation on Outbreak Communications held in Singapore S, editor:: WHO; 2005.

16. United Nations System Influenza Coordination (UNSIC) Asia-Pacific Regional Hub. Simulation exercises on influenza pandemic responses in the Asia-Pacific region. 2008.

17. Standards New Zealand, Standards Australia International. Business continuity management: handbook. Sydney NSW; Wellington N.Z.: Standards Australia International; Standards New Zealand; 2004.

18. Standards Association of Australia. Corporate governance. AS 8003-2003. Sydney N.S.W.: Standards Australia International; 2003.

19. Kerzner H. Project management: a systems approach to planning, scheduling, and controlling. Hoboken: Wiley; 2003.

20. Centers for Disease Control and Prevention. Business Pandemic Influenza Planning Checklist. 2008; Available from: http://www.cdc.gov/flu/pandemic/pdf/businessChecklist.pdf.

21. World Health Organization. WHO Influenza pandemic preparedness checklist November 2004 version. 2004. p. 36.

22. PandemicFlu.gov. Hospital Pandemic Influenza Planning Checklist (website). Available from: http:// www.flu.gov/professional/hospital/hospitalchecklist.html.

23. World Health Organization. WHO checklist for influenza pandemic preparedness planning. 2005. p. 39.

24. Goggin LS, Carcione D, Mak DB, Dowse GK, Giele CM, Smith DW, et al. Chronic disease and hospitalisation for pandemic (h1n1) 2009 influenza in Indigenous and non-indigenous Western Australians. Commun Dis Intell. 2011;35(2):172-6.

25. Massey PD, Miller A, Saggers S, Durrheim DN, Speare R, Taylor K, et al. Australian Aboriginal and Torres Strait Islander communities and the development of pandemic influenza containment strategies: community voices and community control. Health Policy. 2011;103(2-3):184-90.

26. Mounier-Jack S, Coker R. How prepared is Europe for pandemic influenza? Analysis of national plans. Lancet. 2006;367(9520):1405-11. https://doi.org/10.1016/S0140-6736(06)68511-5.

27. Miller A, Durrheim David N. Aboriginal and Torres strait islander communities forgotten in new Australian National Action Plan for human influenza pandemic: ask us, listen to us, share with us. Med J Australia. 2010;193(6):316-7.

28. State Government of Victoria. Victorian Health Management Plan for Pandemic Influenza. In: Victoria DoHS, editor.: Communicable Disease Control Unit Rural and Regional Health and Aged Care Services, Victorian Department of Human Services; 2007. p. 132.

29. Northern Territory Counter Disaster Council. Special Counter Disaster Plan Human Pandemic Influenza-amended 2008 and 2009. In: Northern Territory Department of Health Families, editor. Darwin NT 2006. p. 47.

30. Palache A. Seasonal influenza vaccine provision in 157 countries (2004-2009) and the potential influence of national public health policies. Vaccine. 2011;29(51):9459-66.

31. Brundage JF. Interactions between influenza and bacterial respiratory pathogens: implications for pandemic preparedness. Lancet Infect Dis. 2006;6(5):303-12.

32. Council of Australian Governments. Working Group on Influenza Pandemic Prevention and Preparedness. National Influenza Pandemic Public Communications Guidelines. In: The Department of the Prime Minister and Cabinet, editor. Barton ACT: Commonwealth of Australia; 2008.

33. World Health Organization. WHO Outbreak Communication Guidelines. 2005.

34. Liu BF, Kim S. How organizations framed the $2009 \mathrm{H} 1 \mathrm{~N} 1$ pandemic via social and traditional media: implications for U.S. health communicators. Public Relat Rev. 2011;37(3):233-44.

35. Haddow G. Disaster Communications in a Changing Media World: Buterworth; 2008.

36. CDI. Vaccine preventable diseases and vaccination coverage in Aboriginal and Torres Strait Islander people, Australia 2006-2010. Commun Dis Intell. 2013;37(Suppl):iii-S92. 
37. Council of Australian Government Working Group on Australian Influenza Pandemic Prevention Preparedness. National Action Plan for Human Influenza Pandemic. In: The Department of the Prime Minister and Cabinet, editor. Barton, ACT: Commonwealth of Australia; 2006, 2009. p. 60.

38. Menzies R, Turnour C, Chiu C, McIntyre P. Vaccine preventable diseases and vaccination coverage in Aboriginal and Torres Strait Islander People, Australia 2003 to 2006. Commun Dis Intell. 2008;32:2-67.

39. Couzos S. Why indigenous Australians need their own pandemic plan. Crikey. 2009.

40. Massey PD, Pearce G, Taylor KA, Orcher L, Saggers S, Durrheim DN. Reducing the risk of pandemic influenza in Aboriginal communities. Rural Remote Health. 2009;9(3):1290.

41. Flint S, Davis J. Disproportionate impact of pandemic (H1N1) 2009 influenza on indigenous people in the top end of Australia's Northern Territory. MJA. 2010;192(10):617-22.

42. Cribb L, Owen R, Wallace P. Pandemic Influenza in Australia and the Impact on Aboriginal and Torres Strait Islander Peoples. Listening to Indigenous people about pandemic influenza Inaugural International Workshop; 22.9.2011; Cairns2011.

43. Herceg A, Sharp PG, Arthur CG, Tongs JA. Pandemic (H1n1) 2009 influenza in an urban aboriginal medical service. Med J Australia. 2010;192(10):623.

44. Australian Government. Australian Health Management Plan for Pandemic Influenza (AHMPPI) Important information for all Australians (updated Dec 2009). In: Office of Health Protection in the Department of Health and Ageing, editor. Barton ACT: Commonwealth Copyright Administration Attorney-General's Department Robert Garran Offices,; 2008. p. 147.

45. Government of Australia. APPENDIX to the PROTECT Annex: Guidance for Primary Health Care Workers Providing Care to Aboriginal and Torres Strait Islander people. In: Department of Health and Ageing (DoHA) in consultation with the Office for Aboriginal and Torres Strait Islander Health, editor. V1.0 ed2009.

46. DoH. Australian Government, Department of Health. Australian Health Management Plan for Pandemic Influenza (AHMPPI), April 2014.Available from: http://www.health.gov.au/internet/main/ publishing.nsf/content/519F9392797E2DDCCA257D47001B9948/\$File/AHMPPI.pdf. Accessed 28 September, 2017.

47. Ardagh M. Criteria for prioritising access to healthcare resources in New Zealand during an influenza pandemic or at other times of overwhelming demand. N Zealnd Med J. 2006;119(1243):U2256. Available at: https://www.ncbi.nlm.nih.gov/pubmed/17063196.

48. Itzwerth RL, Macintyre CR, Shah S, Plant AJ. Pandemic influenza and critical infrastructure dependencies: possible impact on hospitals. Med J Australia. 2006;185(10 Suppl):S70-2.

49. Streips K, Simpson DM. Critical infrastructure failure in a natural disaster: initial notes comparing Kobe and Katrina. University of Louisville; 2007.

50. Rodriguez H, Aguirre BE. Hurricane Katrina and the healthcare infrastructure: A focus on disaster preparedness, response, and resiliency. Front Health Serv Manag. 2006;23(1):13-23 discussion 5-30.

51. United States Government Accountability Office. Influenza Pandemic Opportunities Exist to Address Critical Infrastructure Protection Challenges That Require Federal and Private Sector Coordination. 2007.

52. Vespignani A. Complex networks: the fragility of interdependency. Nature. 2010;464(7291):984-5. https://doi.org/10.1038/464984a.

53. Helsloot I, Quinn S. Citizen Response to Pandemics: Authorities' Nightmare or Daydream? APSA 2009 Toronto Meeting Paper. 2009;Available at SSRN: https://ssrn.com/abstract=1450740.

54. Schoch-Spana M, Franco C, Nuzzo JB, Usenza C. Community engagement: leadership tool for catastrophic health events. Biosecurity and Bioterrorism: Biodefense Strategy, Practice, and Science. [https://doi.org/10.1089/bsp.2006.0036]. 2007;5(1):8-25.

55. Leonard EW. After the catastrophe: disaster relief for hospitals. North Carolina Law Review. 2006 85:p. 223. Available at SSRN: https://ssrn.com/abstract=883686.

56. New South Wales Government. NSW Health Interim Influenza Pandemic Action Plan. In: Department of Health, editor. North Sydney 2005, updated Nov 2005. p. 119.

57. Government of South Australia. Pandemic Influenza A Summary of Health's Operational Plan. In: Australia DoHS, editor. Adelaide 2007. p. 24.

58. Queensland Government Queensland Pandemic Influenza Plan 2009. In: Coordination DotPCSP, editor.2009. p. 22.

59. Western Australian Government. Western Australian Government Human Influenza Pandemic Plan. In: Cabinet DotPa, editor. Perth W.A.: Government of Western Australia; 2006, rev 2008. p. 58. 
60. Government of Tasmania Tasmanian Health Action Plan for Pandemic Influenza. In: Services DoHH, editor.2006. p. 51.

Ralf Itzwerth is a PhD from the School of Public Health and Community Medicine, University of New South Wales, Sydney, Australia.

Aye Moa is an MMed (ClinEpi) and an MPH from the School of Public Health and Community Medicine, University of New South Wales, Sydney, Australia.

C. Raina MacIntyre PhD, is a Professor of Infectious Diseases Epidemiology and Head of School, at the School of Public Health and Community Medicine, University of New South Wales, Sydney, Australia. 